\title{
Physico-Chemical Characterization of Novel Epoxy Matrix System Reinforced with Recycled Short Milled Carbon Fibre
}

\author{
Sagar T. Cholake1, Grainne Moran'2, Yu Bai', R. K. Singh Raman",5, X. L. Zhao3, \\ Sami Rizkalla6, Sri Bandyopadhyay ${ }^{*}$ \\ ${ }^{1}$ School of Material Science and Engineering, University of New South Wales, Sydney, Australia \\ ${ }^{2}$ Mark Wainwright Analytical Centre, University of New South Wales, Sydney, Australia \\ ${ }^{3}$ Department of Civil Engineering, Monash University, Clayton, Australia \\ ${ }^{4}$ Department of Mechanical and Aerospace Engineering, Monash University, Clayton, Australia \\ ${ }^{5}$ Department of Chemical Engineering, Monash University, Clayton, Australia \\ ${ }^{6}$ Civil Engineering \& Construction, North Carolina State University, Raleigh, USA \\ Email: S.Bandyopadhyay@unsw.edu.au
}

Received 8 July 2015; accepted 21 August 2015; published 24 August 2015

Copyright (C) 2015 by authors and Scientific Research Publishing Inc.

This work is licensed under the Creative Commons Attribution International License (CC BY).

http://creativecommons.org/licenses/by/4.0/

(c) (i) Open Access

\begin{abstract}
As received recycled short milled carbon fiber (SMCF) reinforced diglycidal ether of bisphenol-A (DGEBA) epoxy matrix materials have been developed by ultra-sonication mixing of SMCF in epoxy then curing at room temperature for nine days. The SMCF with mean diameter $7.5 \mu \mathrm{m}$, and length $100-300 \mu \mathrm{m}$, was used at different loadings i.e. 1, 2, 3, 5 and $10 \mathrm{wt} \%$. Elemental analysis, surface chemistry and crystallography of SMCF were examined using X-ray fluorescence, X-ray photoelectron spectroscopy and X-ray diffraction. Fourier Transform IR spectroscopy confirmed that both in unmodified and SMCF-modified epoxies, 99\% curing was achieved. Surface microhardness study showed a slight increase with $5 \%$ and $10 \%$ SMCF addition. Raman study confirms no structural change in SMCF after incorporation in epoxy. Also, a numerical modelling is implemented to correlate the density of the modified epoxy and SMCF volume fraction/distribution uniformity.
\end{abstract}

\section{Keywords}

Recycled Carbon Fibre, Discontinuous Reinforcement, Resins, Cure Behaviour

\footnotetext{
${ }^{*}$ Corresponding author.

How to cite this paper: Cholake, S.T., et al. (2015) Physico-Chemical Characterization of Novel Epoxy Matrix System Reinforced with Recycled Short Milled Carbon Fibre. Journal of Minerals and Materials Characterization and Engineering, 3, 373-389. http://dx.doi.org/10.4236/jmmce.2015.35040
} 


\section{Introduction}

Epoxy resins are thermoset polymers. Incorporation of filler and continuous fiber reinforcement in the resin can improve mechanical properties and toughness of the composite [1]. In recent years, epoxy is finding advantageous use as a composite matrix in infrastructure (civil engineering) applications [2]-[4] using carbon fiber as reinforcement in epoxies, normally cured at room temperature. A major concern for epoxies has traditionally been their low abrasion/wear resistance, reduced curing in presence of additives, as well as the low fracture properties of the neat epoxies [5]-[7].

Whilst till the last decade fiber reinforced composite materials were regarded as non-recyclable [8] [9], gradual increase in environmental awareness and regulatory guidelines have stopped their disposal into landfill sites [8]. Therefore recycling of carbon fiber has become necessary. This is done in two ways i.e. mechanical and thermal. Mechanical recycling includes powdered carbon fiber with sticking matrix, whereas thermal processes mostly produce clean fibres [10] [11]. However, the recycling of "short" carbon fiber by either means reduces the tensile strength and modulus of the original fiber properties by up to 25\% [10] [12]. Whilst addition of short milled carbon fiber SMCF has shown improvement in wear properties [13], mechanical bonding [14], electrical conductivity [15], and interfacial adhesion [13], there is little or no information in the literature regarding the physico-chemical effects of SMCF addition on curing and/or void/defect content. This paper examines a) the curing kinetics of SMCF/epoxy using Fourier Transform IR spectroscopy [16], b) the D and G band characterization of SMCFs using Raman spectroscopy and c) X-ray diffraction (XRD) to study crystallography and allied variations. The distribution uniformity of SMCF in epoxy matrix is assessed by studying the deviation in volume fraction calculated using practically observed densities of a number of SMCF-epoxy samples.

\section{Materials and Experimental Procedures}

\subsection{Materials}

Commercial SMCF (MF100) supplied by ELG Carbon Fiber Ltd, had average diameter $7.5 \mu$ m, length 100 to $300 \mu \mathrm{m}$, and density $1.8 \mathrm{gm} / \mathrm{cc}$ as per information provided by the supplier. SEM image shown in Figure 1 reveals that SMCFs are randomly oriented.

A general purpose low shrinkage laminating epoxy system (EL-M) consisting of DGEBA and curing agent (hardener) cyclo-aliphatic polyamine was obtained from Barnes Pvt. Ltd, Sydney, Australia.

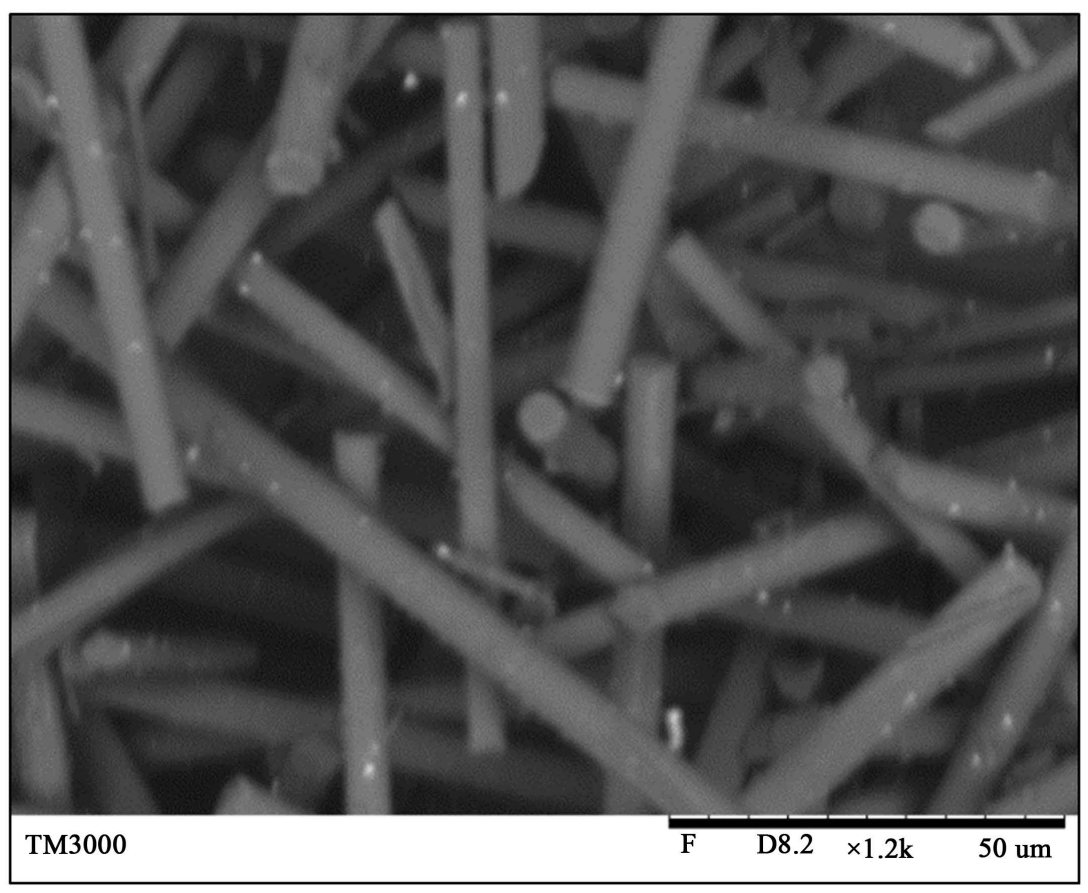

Figure 1. SEM image of SMCF. 


\subsection{Characterisation}

\subsubsection{X-Ray Fluorescence (XRF) Spectroscopy}

Elemental analysis was carried out on pressed pellets of SMCF (wax as a binder) using a PanAlyticalAxios Advanced Sequential wavelength dispersive X-ray Fluorescence (WDXRF) spectrometer equipped with a Rh $4 \mathrm{~kW}$ $\mathrm{X}$-ray tube. Calibration was done with the help of Omanian software.

\subsubsection{X-Ray Photoelectron Spectroscopy}

X-ray photoelectron spectroscopy, the surface characterisation technique used to analyse SMCF, was undertaken using an ESCALAB250Xi with a mono-chromated $\mathrm{Al} \mathrm{K}$ alpha X-ray source $(1486.68 \mathrm{eV})$ operated at $12 \mathrm{~mA}$ emission current and $13 \mathrm{kV}$ anode potential. Survey spectra in the range of $0-1350 \mathrm{eV}$ were recorded with pass energy of $100 \mathrm{eV}$ and a step of $0.5 \mathrm{eV}$, followed by high resolution scanning over selected regions with pass energy of $20 \mathrm{eV}$ and a step of $0.1 \mathrm{eV}$ and the spot size was selected as $500 \mu \mathrm{m}$. All spectra were recorded at a $90^{\circ}$ take-off angle. The surface atomic composition was calculated using Avantage XPS software.

\subsection{Fabrication}

The main interest of this study is to enhance epoxy properties in the field where high temperature curing is not possible such as infrastructure applications (bridge, ship hull, building parts etc.), and therefore, curing was done only at room temperature. The SMCF in the proportions of 1, 2, 3, 5 and $10 \mathrm{wt} \%$ were added to pure epoxy resin and mixed mechanically, followed by ultra-sonication for 45 minutes in a Unisonicbath. After this, the hardener was added and further ultra-sonication was carried out for 15 minutes. The mixture was then transferred to silicone rubber molds to produce SMCF modified epoxy matrix sheets in the form of single edge notch bending (SENB) test samples (ASTM Standard D5045)for tests for this research. Curing was carried out at ambient laboratory temperature $\left(21^{\circ} \mathrm{C} \pm 4^{\circ} \mathrm{C}\right)$, with maximum curing time as 9 days. FTIR peaks were measured after every 24 hours of curing, and it was observed that after 8 days of curing there was no further change in FTIR peaks.

In the results described below, the epoxy/SMCF composites are designated as ESMCF 00 (neat epoxy), ESMCF 01, ESMCF 02, ESMCF 03, ESMCF 05 and ESMCF 10 representing the wt\% of SMCF added viz 1\%, $2 \%, 3 \%, 5 \%$, and $10 \%$.

\subsection{Sample Characterization: FTIR, Raman and XRD}

FTIR Spectra were measured using a Perkin Elmer Spectrum 100 FT-IR spectrometer, at a resolution of $4 \mathrm{~cm}^{-1}$ and collecting 16 scans. SMCF and polyamine were characterized by making $\mathrm{KBr}$ discs and measuring transmission spectra. The spectrum of liquid DGEBA was obtained by ATR applied to a KBr disc [17]. Peak areas, representing $\mathrm{C}-\mathrm{O}-\mathrm{C}$ bonds were measured in absorbance mode using E-FTIR software.

Raman spectra were measured using an InVia Raman microscope with laser excitation at $514 \mathrm{~nm}$ and a low laser power (10\% was selected after checking) to avoid overheating of the sample [17]. Static mode was used with 100 accumulations with middle point at $1400 \mathrm{~cm}^{-1}$ in order to obtain a scan from 950 to $1850 \mathrm{~cm}^{-1}$ the range containing $\mathrm{D}$ and $\mathrm{G}$ peaks of carbon.

XRD: Wide angle X-ray diffraction (WAXD) traces were obtained in the $2 \Theta$ range of $10^{\circ}-80^{\circ}$ using the PANalytical Xpert Multipurpose X-ray Diffraction System (MPD). Crystallinity is calculated by taking the ratio of the area under the peaks to area under the complete X-ray diffraction trace [18]. The area under the peak was determined by setting a baseline for amorphous scattering and subtracting the baseline intensities from total diffraction [19]. The method [20] of estimating other parameters such as width (b. i.e. full width at half intensity FWHM) and peak intensity (I) is shown in Figure 2 by correcting the baseline of XRD peak at $18^{\circ} \mathrm{C}$.

\subsection{Density and Microhardness Measurement}

Density was measured by the Archimedes principle and for this samples were cut in square shapes in various sizes. Three cut pieces from five different samples of the same category were studied and the average value taken as the density of the composite. After determining the density $\left(\rho_{c}\right)$ of composite pieces, the volume fraction of the SMCF particles $\left(V_{f}\right)$ was calculated from the Equation (1) [21]: 


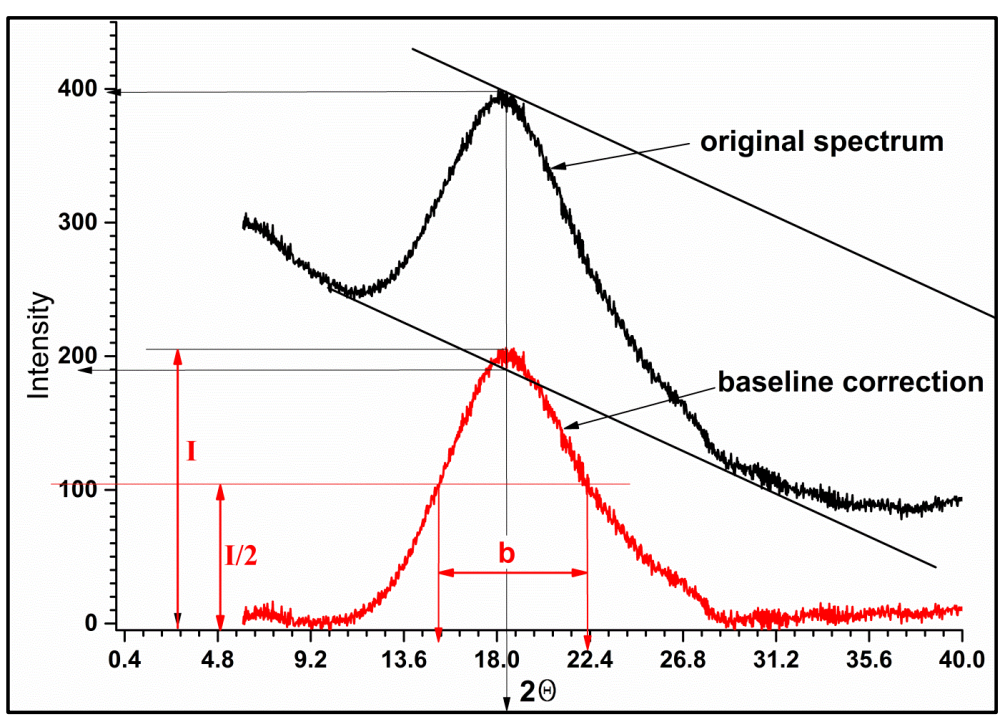

Figure 2. Graphical representation of selection of baseline and estimation of b and I for XRD peaks, as shown for one of the SMCF-epoxy sample containing $10 \mathrm{wt} \%$ of SMCF.

$$
\% V_{f}=\left(1-\frac{\rho_{f}-\rho_{c}}{\rho_{f}-\rho_{m}}\right)
$$

where, $\rho_{f}$ (equal to $1.8 \mathrm{gm} / \mathrm{cc}$ ) and $\rho_{m}$ are fiber and cured epoxy resin (neat epoxy) densities.

Surface hardness, representing abrasion resistance, is calculated in terms of Vickers microhardness $\left(H_{v}\right)$ at constant maximum load of $0.3 \mathrm{~kg}$ (which was decided after a number of trials at different loads). At this load of $0.3 \mathrm{~kg}$, a large area is covered including matrix and reasonable amount of SMCF particles. For each SMCFepoxy category, five indentations were made at a sufficient distance from each other on three samples. After removal of the load, the Vickers micro hardness was derived from the residual projected area (plastic deformation) of the indentation and the average value was noted.

\section{Results and Discussion}

\subsection{SMCF Characterization}

\subsubsection{XRF}

Table 1 shows the elemental analysis of SMCF using XRF-as it appears, SMCF used in this study had 96.7\% carbon and the balance consists of impurities including oxides of $\mathrm{Na}, \mathrm{Mg}, \mathrm{Al}, \mathrm{Fe}, \mathrm{Ti}$ and $\mathrm{Ca}$ : $\mathrm{Fe}_{2} \mathrm{O}_{3}$ constitutes the largest wt\% i.e. $1.026 \%$ followed by $\mathrm{SiO}_{2}(0.724 \%)$.

\subsubsection{XPS}

Surface chemistry of SMCF studied by XPS is shown in Figure 3 and Figure 4. Survey scan (Figure 3(a)) shows three main peaks as typically observed in virgin carbon fibers showing presence of carbon, oxygen and nitrogen [22]-[25]. XPS scans (Figures 4(a)-(d)) reveal that among all the impurities found in SMCF in the XRF study (see Table 1), silicon, sodium and calcium present on the surface which probably came from the recycling process or as residue of the parent source of SMCF composite. The carbon peak is located around 284 $\mathrm{eV}$ in which a strong C1s A peak can be assigned to graphitic peak at $284.38 \mathrm{eV}$ and other small peaks in the tail at higher binding energy represent oxides. The oxide to graphite ratio found was 0.2 . The weakest oxide peak named as $\mathrm{C} 1 \mathrm{~s} \mathrm{~F}$ at $290.78 \mathrm{eV}$ in Figure 3 can be assigned to chemical group $-\mathrm{CO}_{3}$ and other C1s E, C1s D and $\mathrm{C} 1 \mathrm{~s} \mathrm{C}$ at 289.08, 287.88 and $286.38 \mathrm{eV}$ correspond to $-\mathrm{COOH},-\mathrm{C}=\mathrm{O}$ and $-\mathrm{OH}$ groups respectively. FTIR spectrum of SMCF shown in Figure 5 also supports this conclusion as discussed in the next section.

The best fit for the oxygen peak (O1s) was up to three component peaks as shows in Figure 3(c). This indicates that SMCF is not significantly oxidized as oxygen was present on the SMCF surface in other forms than 


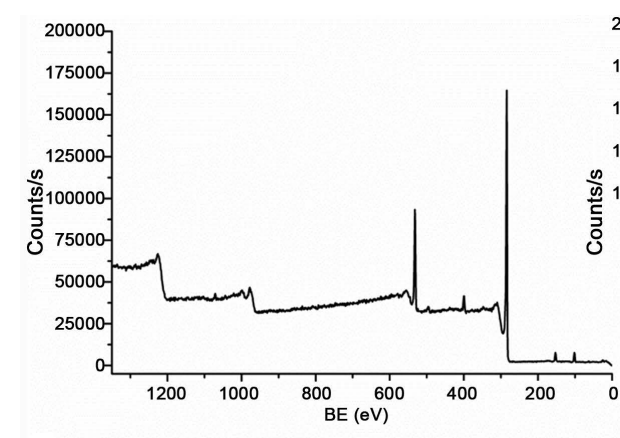

(a)

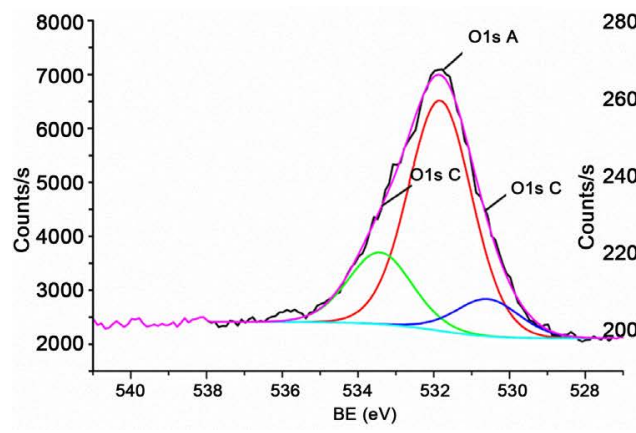

(c)

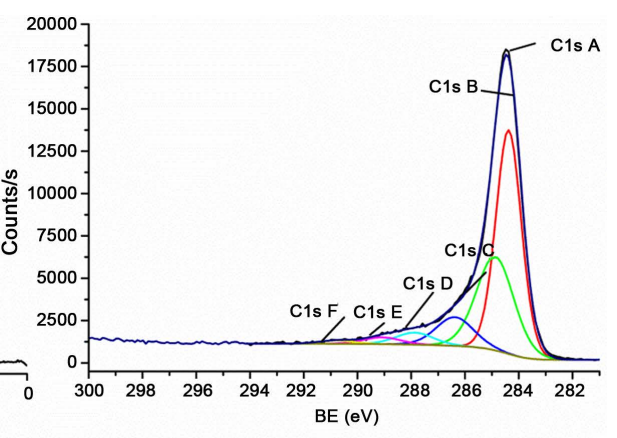

(b)

Figure 3. XPS scans of surface analysis of SMCF showing (a) Survey scan in the range 0 - 1350 eV; (b) Carbon near $284 \mathrm{eV}$; (c) Oxygen near $532 \mathrm{eV}$; and (d) Nitrogen at $480 \mathrm{eV}$.

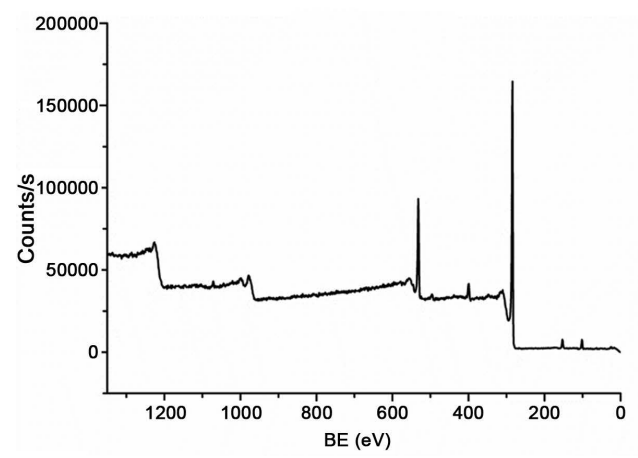

(a)

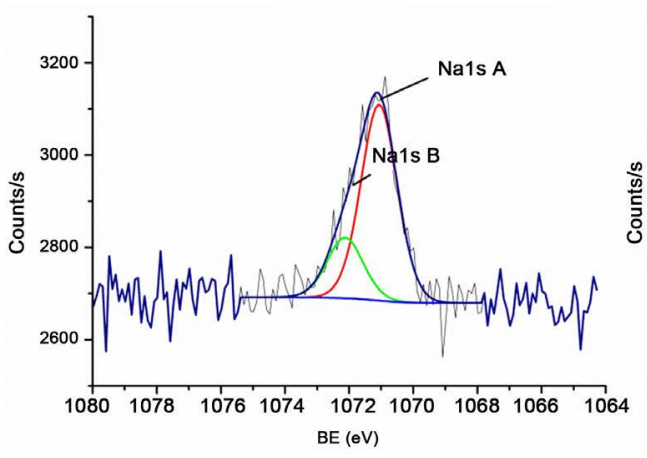

(c)

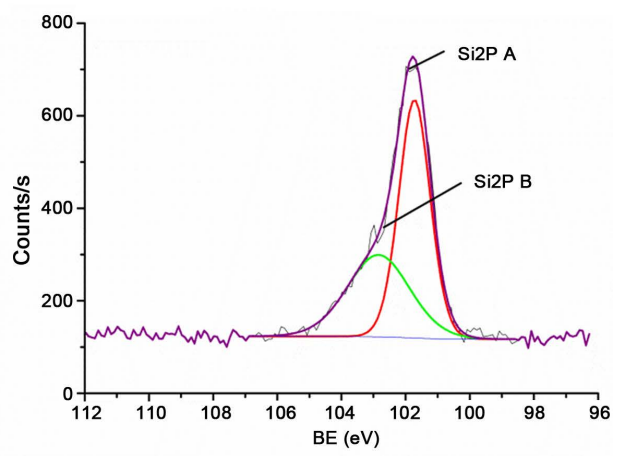

(b)

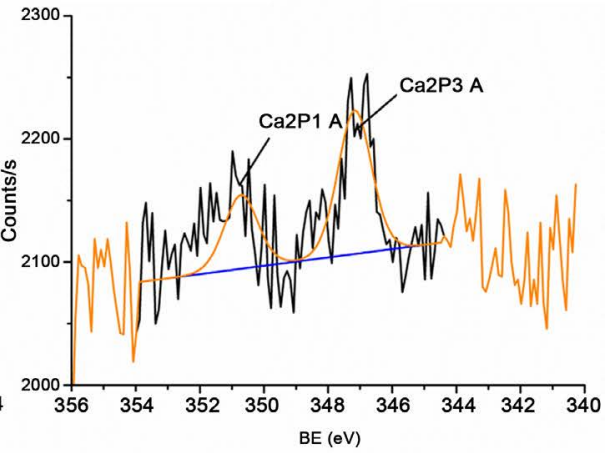

(d)

Figure 4. XPS scans of SMCF showing (a) Survey in the range $0-1350 \mathrm{eV}$ and impurities such as (b) Silicon near $102 \mathrm{eV}$; (C) Sodium near $1071 \mathrm{eV}$; and (d) Calcium around $350 \mathrm{eV}$. 


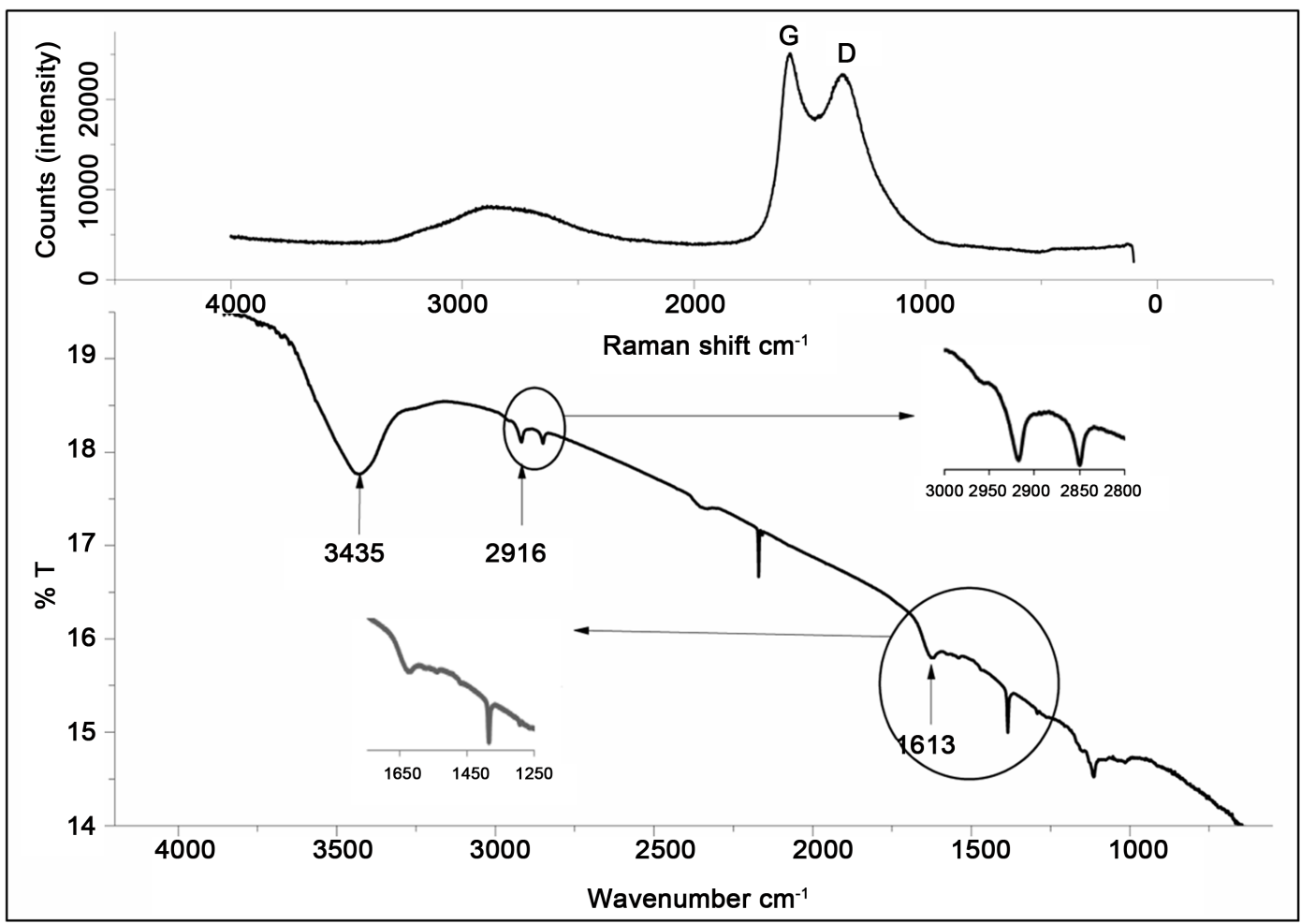

Figure 5. Raman (top) and FTIR spectra of SMCF used in this study.

Table 1. XRF elemental analysis data for SMCF impurities.

\begin{tabular}{|c|c|c|}
\hline Element & wt\% & State \\
\hline $\mathrm{Na}$ & 0.117 & $\mathrm{Na}_{2} \mathrm{O}$ \\
\hline $\mathrm{Mg}$ & 0.040 & $\mathrm{MgO}$ \\
\hline $\mathrm{Al}$ & 0.079 & $\mathrm{Al}_{2} \mathrm{O}_{3}$ \\
\hline $\mathrm{Si}$ & 0.724 & $\mathrm{SiO}_{2}$ \\
\hline $\mathrm{P}$ & 0.079 & $\mathrm{P}_{2} \mathrm{O}_{5}$ \\
\hline S & 0.050 & $\mathrm{SO}_{3}$ \\
\hline $\mathrm{Cl}$ & 0.034 & $\mathrm{Cl}$ \\
\hline K & 0.074 & $\mathrm{~K}_{2} \mathrm{O}$ \\
\hline $\mathrm{Ca}$ & 0.522 & $\mathrm{CaO}$ \\
\hline $\mathrm{Ti}$ & 0.053 & $\mathrm{TiO}_{2}$ \\
\hline $\mathrm{Cr}$ & 0.094 & $\mathrm{Cr}$ \\
\hline Mn & 0.015 & $\mathrm{MnO}$ \\
\hline $\mathrm{Fe}$ & 1.026 & $\mathrm{Fe}_{2} \mathrm{O}_{3}$ \\
\hline $\mathrm{Ni}$ & 0.046 & $\mathrm{Ni}$ \\
\hline $\mathrm{Cu}$ & 0.021 & $\mathrm{Cu}$ \\
\hline $\mathrm{Zn}$ & 0.311 & $\mathrm{Zn}$ \\
\hline Total impurities & 3.3 & (Carbon is $96.7 \%$ ) \\
\hline
\end{tabular}


only $\mathrm{C}=\mathrm{O}$ which is usually observed in oxidized carbon fiber at $530 \mathrm{eV}$. These other forms of oxygen could be either chemisorbed oxygen or absorbed water and C-OH and/or C-O-C groups as suggested by O1s B and O1s A peaks at 533.42 and $531.83 \mathrm{eV}$ respectively. The other significance of the O1s peak is to evaluate the reactive sites in terms of $\mathrm{O} / \mathrm{C}$ ratio, available on the surface of the SMCF. This ratio is found to be 0.15 in present SMCF which is in the range of other recycled carbon fiber O/C ratios i.e. from 0.10 to 0.3 [22]-[24] [26] [27] and higher than nano sized graphite such as carbon nano tubes (0.03 for pristine CNT) whereas that of epoxy is 0.23 [24]. A lower $\mathrm{O} / \mathrm{C}$ ratio indicates that less amount of oxygen containing functional groups are present on the surface of the SMCF resulting in less active surface area available for chemical bonding with epoxy.

Figure 4 shows the XPS scans of the impurities present on the surface of SMCF of which Si has the highest proportion. The peak observed for Si at $101 \mathrm{eV}$ (Figure 4(b)) is a result of two peaks at 101.82 and $102.7 \mathrm{eV}$ labeled as Si2P A and Si2P B respectively. One of the possible reasons of the presence of Si as impurity element on SMCF surface can be the use of siloxane (e.g. cross-linked polysiloxane [28]) release agent on the virgin carbon fiber (CF) for better interfacial bonding between CF and matrix material. Some of this agent may be left after the recycling process in the form of oxides. Low BE peak Si2P A represents the Si directly bonded to two oxygen atoms and the higher electronegativity peak at $102.7 \mathrm{eV}$ represents three oxygen atoms bonded to Si.

\subsubsection{Raman and FTIR Spectra}

The FTIR spectrum of the SMCF shown in Figure 5 reveals the presence of the polar groups hydroxyl (-OH), carboxyl (-COOH) and carbonyl (-C=O) as suggested by respective peaks [17] observed at 3435, 2916 and 1613 $\mathrm{cm}^{-1}$. Researchers [29]-[31] believe that these groups are formed during the SMCF recycling process. On the other hand, the existence of the corresponding peaks of these groups in the XPS spectrum of virgin carbon fibers [22] may tell a different story. The presence of these polar groups have proved advantageous in the wetting process [17]. Among these four oxygen containing functional groups, - $\mathrm{OH}$ and $-\mathrm{COOH}$ contribute more in forming hydrogen bonds with epoxy because of their proton donor and acceptor nature [27].

\subsection{Epoxy/SMCF System Characterization}

\subsubsection{Crosslinking}

Characteristic peaks of the epoxy group are seen in DGEBA at 915 and $3056 \mathrm{~cm}^{-1}$ (see Figure 6) those correspond to C-O-C and C-H bending and stretching vibration modes respectively. Curing of DGEBA is done by the opening of epoxy group and consequently reducing area of the peaks mentioned above [32]-[37]. Therefore 915 and $3056 \mathrm{~cm}^{-1}$ peaks are normalised with the $1183 \mathrm{~cm}^{-1}$ peak as it doesn't participate in the curing reaction [16] [35] [36] [38]. Gradual decrease of these peaks is generally taken to represent the extent of conversion of the epoxy groups [32]. Using this approach, curing time was decided in presence of SMCF as that when the constant

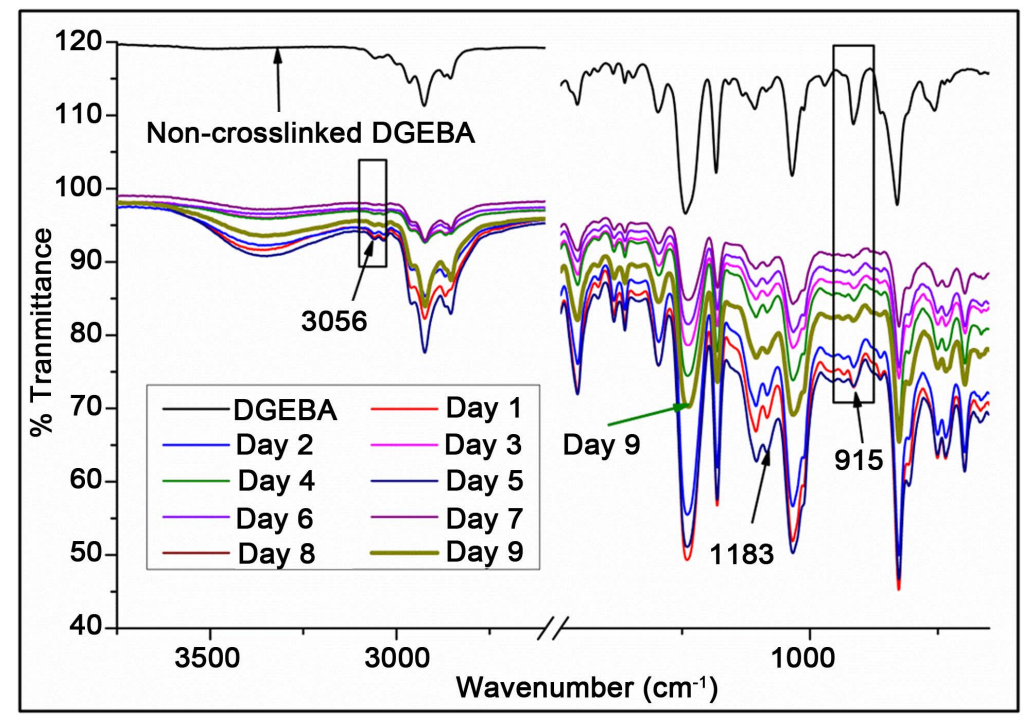

Figure 6. FTIR spectra of ESMCF 01 over 9 days of curing. 
maximum crosslinking was achieved for available epoxy/hardener mixture. Crosslinking $(\alpha)$ is calculated using Equation (2) [36], where A refers to the area under peak calculated in absorption mode.

$$
\alpha=1-\frac{\left(\mathrm{A}_{915 t}\right)\left(\mathrm{A}_{11830}\right)}{\left(\mathrm{A}_{1183 t}\right)\left(\mathrm{A}_{9150}\right)}
$$

where $A_{11830}$ denotes the area under this peak at the start of the experiment and $A_{1183 t}$ represents the area after a certain curing time t. Similarly $A_{915}$ represents the area under the peak at $915 \mathrm{~cm}^{-1}$ at different times.

Figure 7 shows that for ESMCF 01, using 3056 and $915 \mathrm{~cm}^{-1}$, about $70 \%$ crosslinking is achieved within one day with transformation into a partially cured system. This glassy state slows down the further crosslinking process [39] over the following 7 - 8 days and maximum (optimum) crosslinking is seen after day 8 i.e. 99.1\% cross-linking determined from $915 \mathrm{~cm}^{-1}$ and $89 \%$ crosslinking determined from $3056 \mathrm{~cm}^{-1}$ peak which is found to be similar to that of neat epoxy curing. The extent of curing vs time features of Figure 7 is consistent with the volumetric observations reported for curing of a dental epoxy resin [40].

All the compositions from neat epoxy up to 10\% SMCF/epoxy composites displayed 99\% curing/cross linking at $915 \mathrm{~cm}^{-1}$ peak and $89 \%$ curing/crosslinking at $3056 \mathrm{~cm}^{-1}$ after 8 days. The $915 \mathrm{~cm}^{-1}$ data is taken to be more quantitative, because the $3056 \mathrm{~cm}^{-1}$ peak is overlapped with other peak (see Figure 6) hence makes it difficult to accurately calculate the \% cross linking.

FTIR spectroscopy confirms that the presence of SMCF does not interfere with chemical reaction taking place between the curing agent and the epoxy ring.

\subsubsection{Raman Shift and XRD of ESMCF System}

Unlike the Raman spectrum of single crystal graphite [41], SMCF shows two peaks, typical of distorted graphitic carbon where the $\mathrm{D}$ band $\left(1351 \mathrm{~cm}^{-1}\right)$ [42] [43] represents the $\mathrm{A}_{1 \mathrm{~g}}$ mode derived from defect sites in carbon fiber and the $\mathrm{G}$ band at $1590 \mathrm{~cm}^{-1}$ represents the crystalline structure [43] [44]. This can be seen in Figure 5 top. The Raman spectra of all ESMCF series taken on the sample top surface were observed to be the same as neat epoxy Raman spectra. This leads to the possibility of no SMCF particles on the surface of the samples. Therefore, in order to study the Raman spectra of SMCF in the epoxy system, samples were studied on the fracture surface by focusing the laser beam individually on the SMCF and epoxy in the fracture region of composite, as shown in Figure 8. Figure 8(a) and Figure 8(b) show the laser focusing locations on the top surface of the sample on epoxy rich region and fiber underneath the epoxy respectively.

Again the Raman spectra obtained from the epoxy region on top surface and fracture surface (Figure 8(a) and Figure 8(d)) were similar to each other and to that of the pure epoxy as shown in Figure 9. This confirms that all carbon peaks of epoxy are unchanged after adding SMCF.

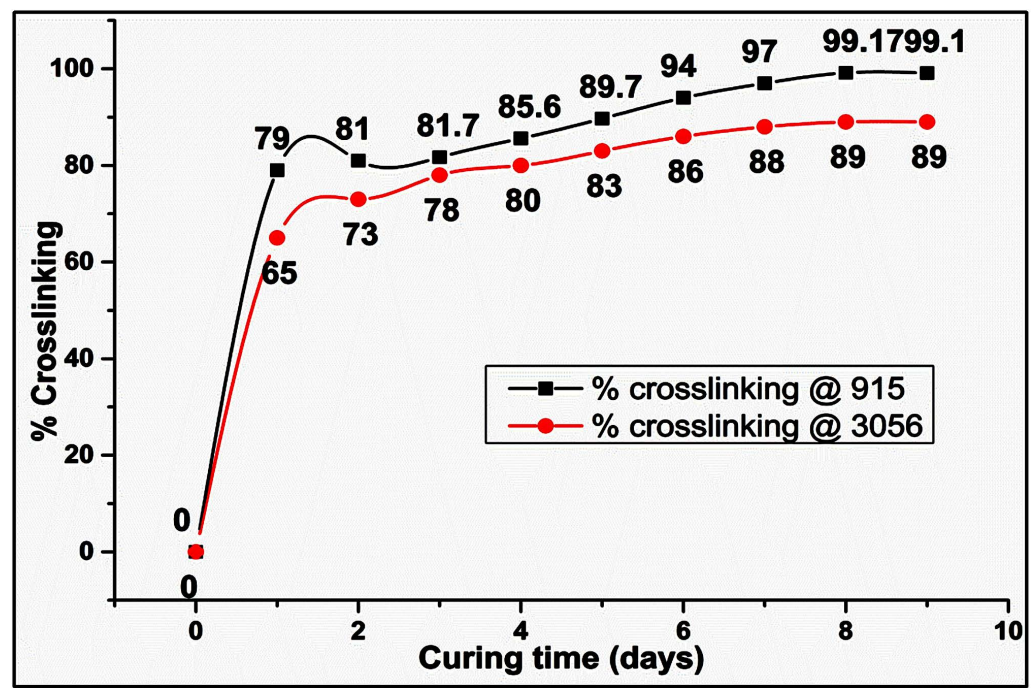

Figure 7. Typical \% crosslinking/curing vs curing time of ESMCF 01 as calculated from 915 and $3056 \mathrm{~cm}^{-1}$ peaks. 


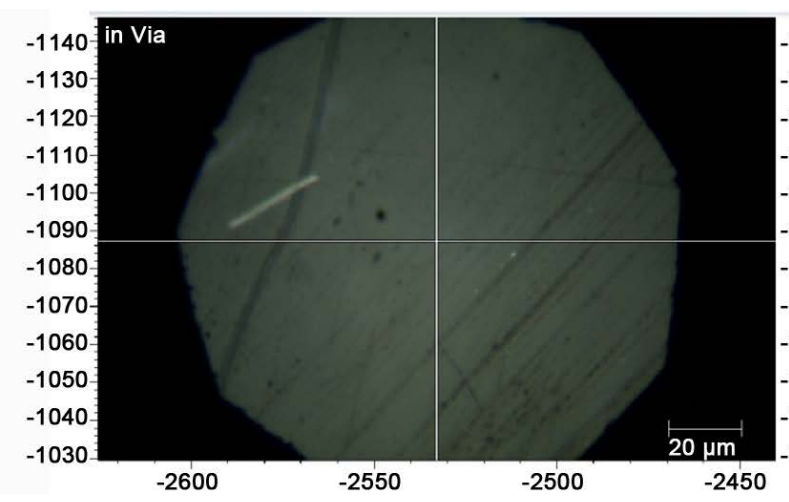

(a)

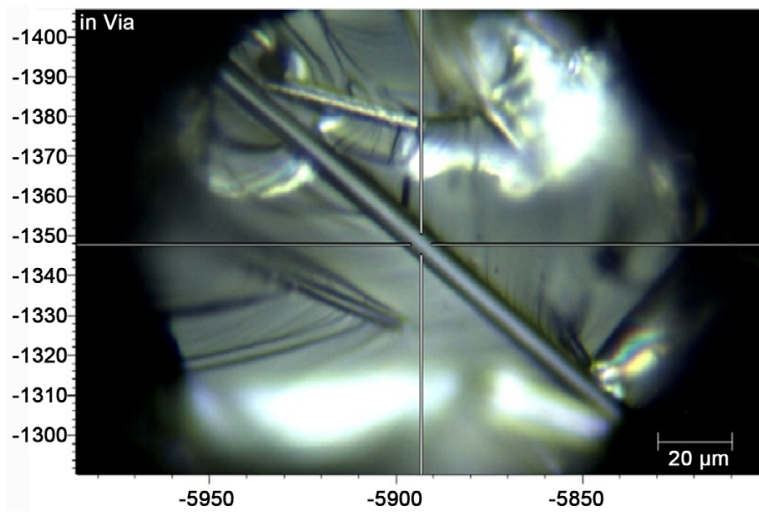

(c)

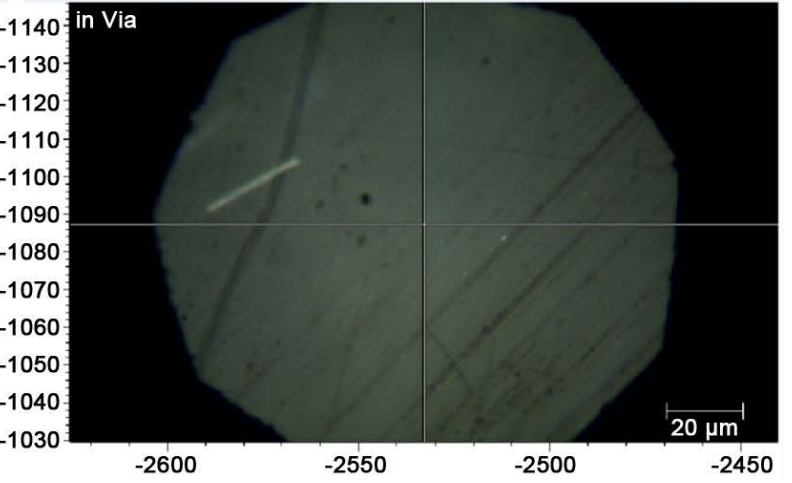

(b)

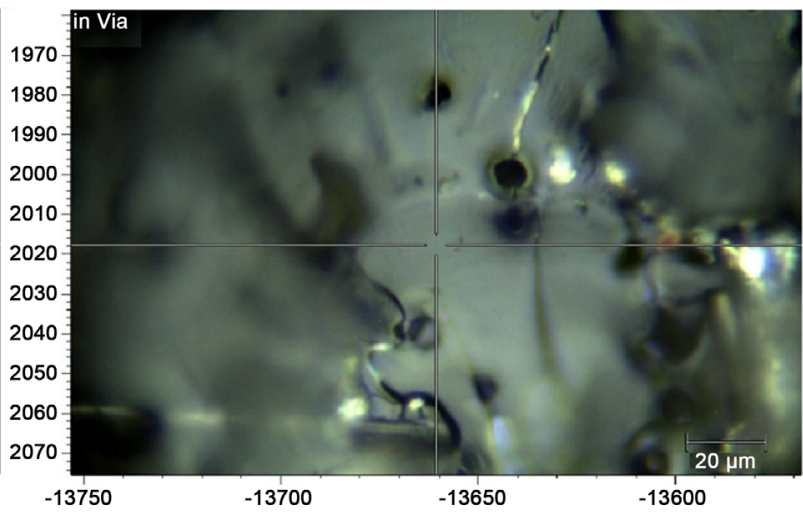

(d)

Figure 8. Laser focusing in Raman microscopy of (a) Epoxy surface; (b) Fibre underneath the epoxy (c) SMCF on fracture surface; (d) Fracture surface of SMCF-modified epoxy matrix. The scale on right bottom corner represents $20 \mu \mathrm{m}$.

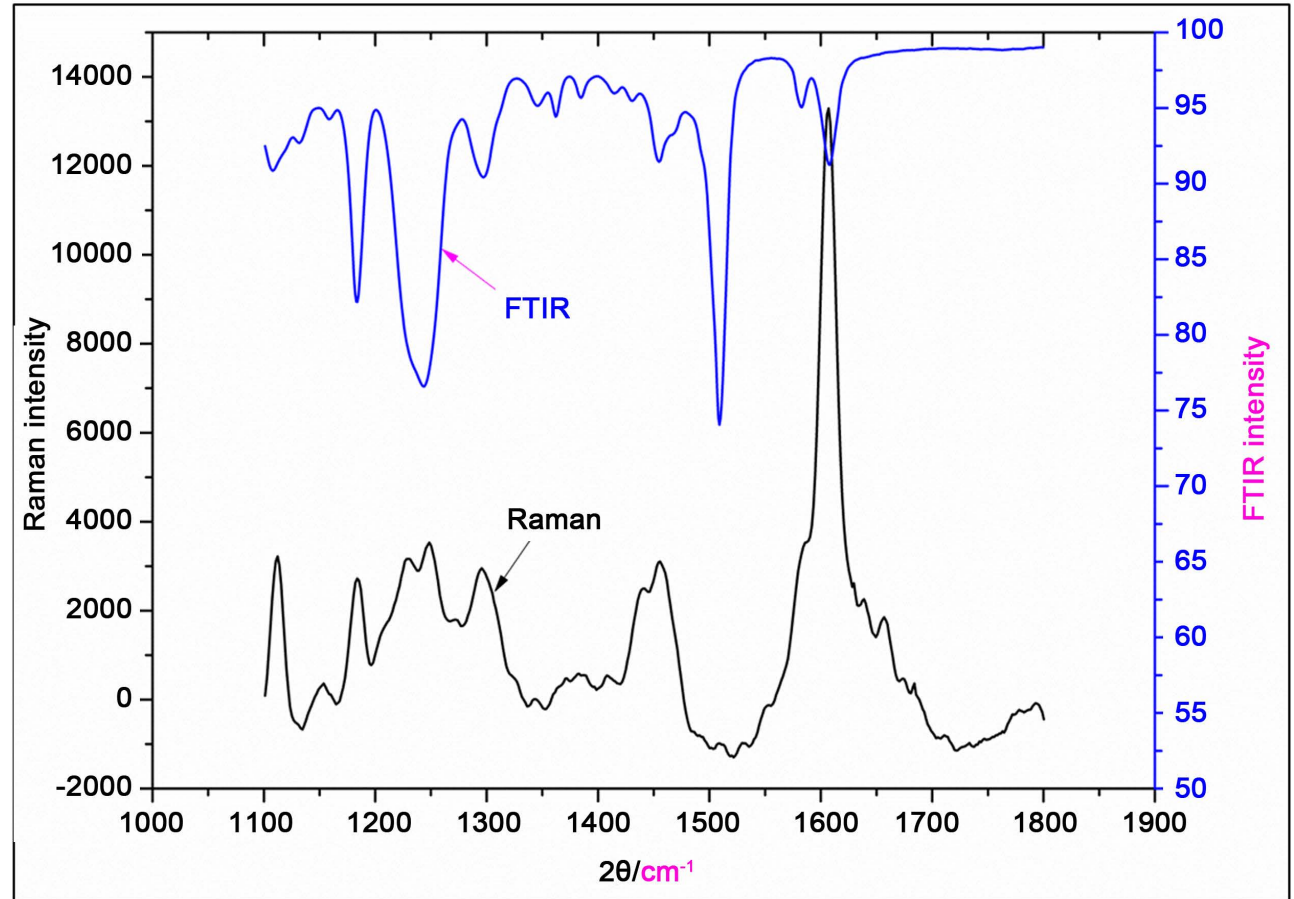

Figure 9. Raman and FTIR spectra of neat epoxy. 
As can be seen in Figure 10, the disordered and crystalline carbon peaks observed in neat SMCF remain unchanged after adding to epoxy. The $\mathrm{I}_{\mathrm{D}} / \mathrm{I}_{\mathrm{G}}$ [43] [45] (also $\mathrm{I}_{\mathrm{D}} /\left(\mathrm{I}_{\mathrm{D}}+\mathrm{I}_{\mathrm{G}}\right.$ ) [42]) ratio was also found to be very similar for SMCF and all ESMCF series. SMCF particles were studied in both transverse and longitudinal directions. These results are different to the results obtained by Bal [45] where the $I_{D} / I_{G}$ ratio was reduced in a SMCF and epoxy composite system which was cured in a refrigerator.

\subsubsection{XRD}

The XRD results (Figure 11) confirm the amorphous nature of both ESMCF 00 (neat epoxy) and SMCF by the symmetric broad peaks observed at $2 \Theta$ values $19^{\circ}$ and $25^{\circ}$ respectively [46]. The peak at $42^{\circ}$ in the SMCF spectrum indicates the presence of $\mathrm{Fe}\left(\mathrm{Fe}_{2} \mathrm{O}_{3}\right)$ and other impurities in the SMCF fiber as also found by XRF and XPS [47]. The amorphous peak in SMCF at $25^{\circ}$ corresponds to $\mathrm{hkl}=002$ index whereas that for ESMCF 00 is midway between $\left(1 / 41 / 40\right.$ and $(1 / 2,0,0)$, plus another peak at $42^{\circ}$ corresponding to $h k l=100$ [20]. The absence of a sharp peak at 200 shows that only amorphous carbon is present in SMCF [20]. At the same time, the peak width observed in SMCF is narrower than that observed in epoxy indicating the more amorphous nature of epoxy than SMCF.

Incorporation of SMCF in the epoxy resin resulted in a final diffraction pattern of reduced intensity of halo (002) peak of ESMCF system with increased relative width (measured in terms of b i.e. FWHM which is full width of the peak in rad at half of the intensity (I)). This implies that the addition of SMCF to epoxy has reduced the crystallinity of the epoxy by a small extent. A close view of the amorphous peak (inset in Figure 11) clarifies that there is no well-defined trend observed in the decrease of crystallinity, whereas I/b ratio and area calculation as explained in experimental section proved that ESMCF 03 shows the highest crystallinity (but less than neat epoxy i.e. ESMCF 00) and ESMCF 10 shows the lowest crystallinity among all SMCF blended epoxy systems.

Depending upon the change observed in $2 \Theta$ (from $18.4^{\circ}$ to $19.05^{\circ}$ ) and $\mathrm{b}$ (from $0.115^{\circ}$ to $0.133^{\circ} \mathrm{rad}$ ) and using their relationship [48]-[51] with XRD parameters the following can be stated. Factors depending on $b$ such as crystallite size, micro strain, dislocation density and dislocation parameter are increased while on the other hand interchain separation and interplane distance are decreased to a small extent after SMCF addition.

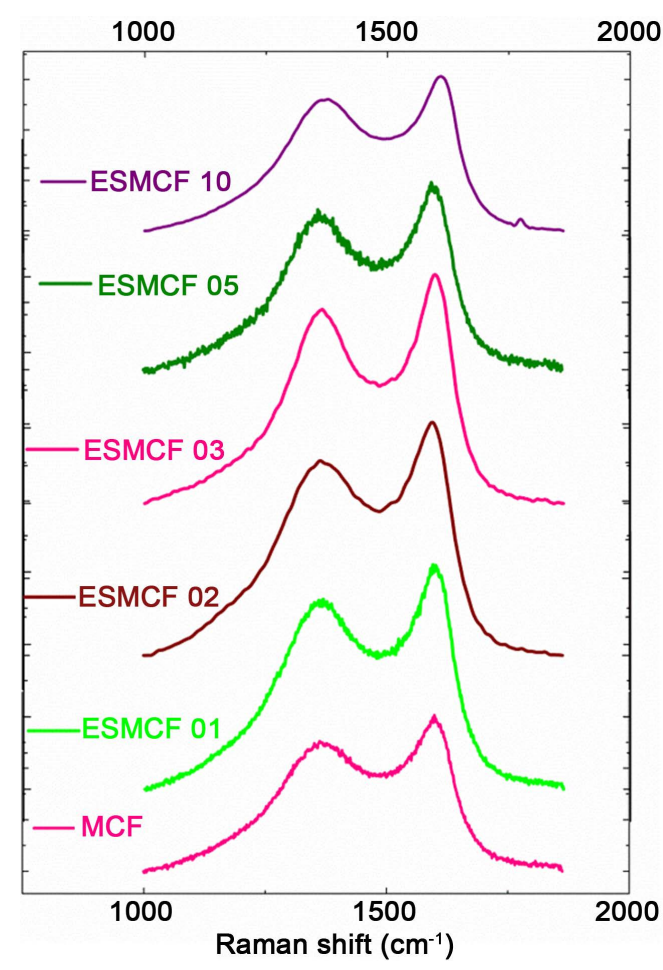

Figure 10. D and G peaks observed in SMCF and EMSCF series on fracture surface. 


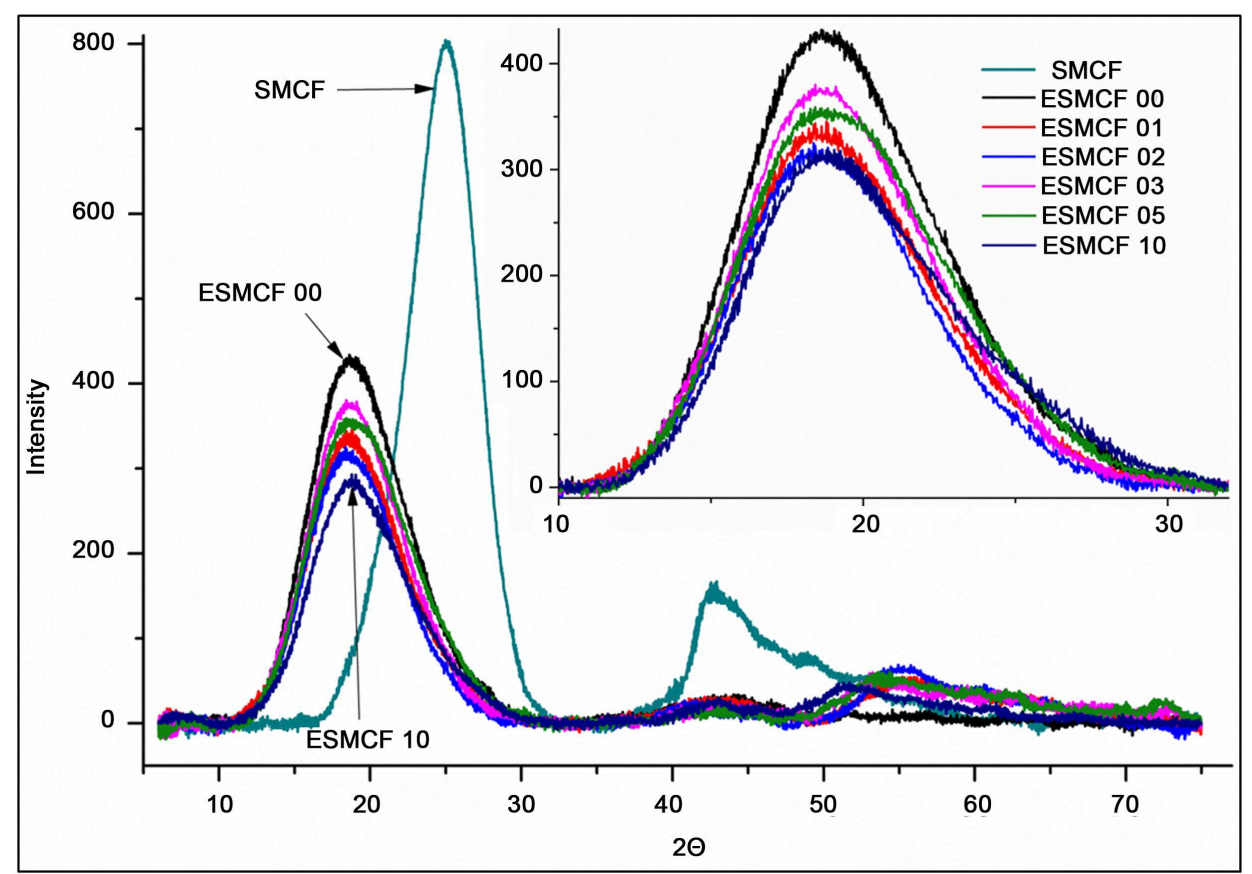

Figure 11. XRD scattering of SMCF and ESMCF series. Inset shows enlarged image of halo peak of ESMCF series.

\subsection{Density, Volume Fraction and Microhardness}

Table 2 shows density and volume fraction $\left(V_{f}\right)$ determined by theoretical calculations (rule of mixture) and experimentally (Archimedes principle-according to ASTM D792) [52]. A large variation was observed between the calculated density $(1.08 \mathrm{gm} / \mathrm{cc})$ and experimental density $(1.145 \mathrm{gm} / \mathrm{cc})$ which can be attributed to the crosslinking effect between DGEBA and hardener resulting in shrinkage of the cured epoxy samples (the shrinkage was found to be $\sim 8 \%$ ) which reduces the volume and therefore, increases the density. Therefore to allow for the effect of shrinkage, the density of $1.145 \mathrm{gm} / \mathrm{cc}$ was used as shown in Table 2 and Figure 12. A small difference between these two values is believed to be the result of the loss of the material during fabrication as no change in shrinkability was found after addition of SMCF.

Reduced density indicates more SMCF fiber loss during casting than epoxy possibly because of SMCF fiber settlement at the bottom of the vessel glass. Therefore in order to find out the actual amount of SMCF in the modified epoxy, the volume fraction of SMCF was calculated as shown in Figure 12 and Table 2. Figure 12 shows the average value of 15 samples and it can be concluded from the small standard deviation bars (from mean values) that the dispersion of SMCF in the epoxy matrix is better at higher wt $\%$ than lower which show higher deviation in density and volume fraction.

Numerous glassy and semicrystalline polymer blends obey the additivity law of microhardness [21] [53] [54] but in this study the microhardness of epoxy/SMCF is decreased in initial stages (Figure 13). This behaviour of the system in this study is similar to that of polyethylene/polypropylene blends observed by Balta et al. [55] which also do not follow the rule of additivity. In the present study the microhardness value of the system decreased on initial loading (i.e. $1 \mathrm{wt} \%$ ) and thereafter starts increasing with increasing loading (from $2 \mathrm{wt} \%$ ) and surpasses the microhardness of neat epoxy at $5 \mathrm{wt} \%$ loading. ESMCF microhardness (Figure 13) shows the increase of $H_{v}$ as a function of volume fraction $\left(V_{f}\right)$ of SMCF. This can relate to increase in dislocation density and micro-strain as observed in XRD. Another possible reason can be that epoxies have modulus of elasticity typically of 3 GPA, whereas the SMCF has a very high modulus of elasticity and hardness/rigidity. And higher number of SMCF on surface shows higher microhardness in case of EMCF 05 and 10 restricting the plastic deformation due to indenter. The increasing part of the microhardness is described by the following equation:

$$
H_{v}=0.5183 V_{f}+13.633
$$




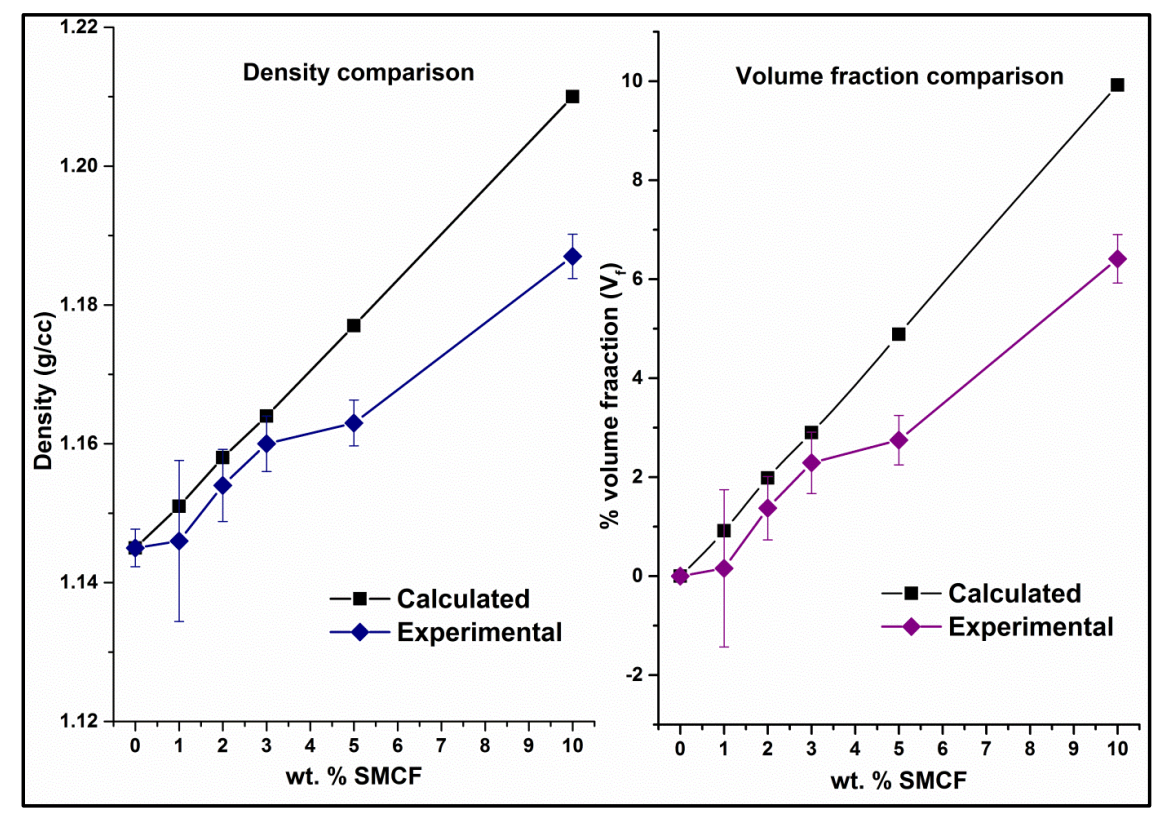

Figure 12. Comparison of theoretical and experimental values of density and \% volume fraction of ESMCF series.

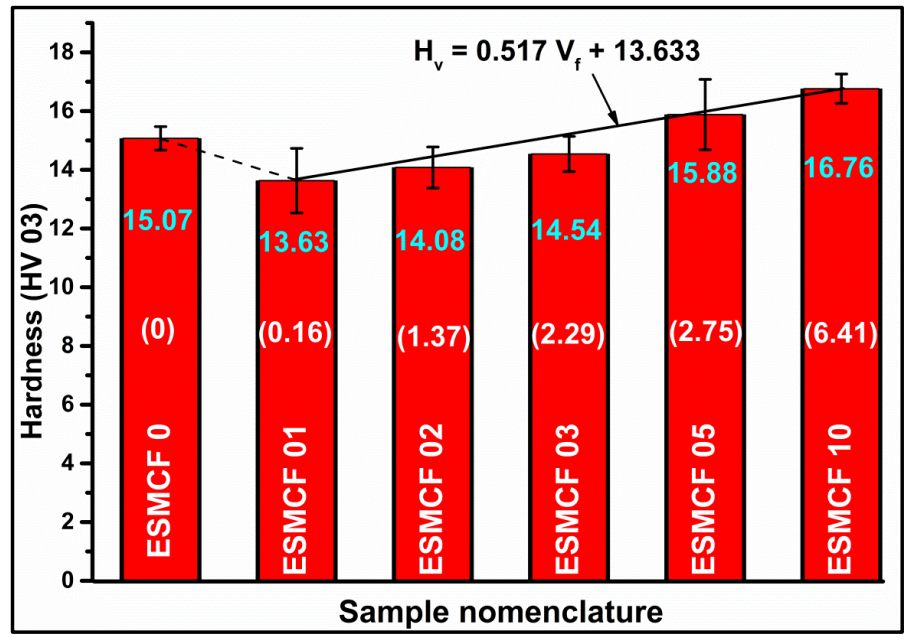

Figure 13. Vickers microhardness at $0.3 \mathrm{Kg}$ load of neat epoxy and epoxy/SMCF blends showing a linear relation with vol\%. Note: Middle values on the bars in brackets show volume fraction of SMCF of corresponding sample.

Table 2. Theoretical and experimental values of density and volume fraction of ESMCF series along with surface microhardness hardness under 300 gms load (HV03).

\begin{tabular}{cccccc}
\hline \multirow{2}{*}{ EMCF } & \multicolumn{2}{c}{ Density $\left(\mathbf{g} \cdot \mathbf{c m}^{-\mathbf{3}}\right)$} & \multicolumn{2}{c}{ \% Volume fraction $\left(V_{f}\right)$} & HV03 \\
\cline { 2 - 5 } & Calculated & Experimental & Theoretical & Experimental & \\
\hline $\mathbf{0 0}$ & 1.145 & 1.145 & 0 & 0 & 15.72 \\
$\mathbf{0 1}$ & 1.151 & 1.146 & 0.916 & 0.157 & 13.63 \\
$\mathbf{0 2}$ & 1.158 & 1.154 & 1.984 & 1.374 & 14.08 \\
$\mathbf{0 3}$ & 1.164 & 1.160 & 2.900 & 2.290 & 14.54 \\
$\mathbf{0 5}$ & 1.777 & 1.163 & 4.885 & 2.748 & 15.88 \\
$\mathbf{1 0}$ & 1.210 & 1.187 & 9.923 & 6.412 & 16.76 \\
\hline
\end{tabular}




\subsection{Low Magnification View of SMCF Distribution in Epoxy Matrix}

Figure 14 is the qualitative indication of the dispersion and uniformity distribution of the SMCF in the epoxy matrix from 1 to $10 \mathrm{wt} \%$, which was achieved without use of any surfactant. The control sample neat epoxy (0\% SMCF) naturally shows no fiber or any impurities. For samples containing 1\%, 2\%, 3\%, 5\% and 10\% SMCF, interestingly there is no agglomeration of the SMCF which is a good indication of a successful ultrasonication technique. This achievement will form the basis of the further study of this work in terms of improved flexural modulus as well as improved fracture properties by addition of SMCF to epoxy as will be related/explained to a quantitative correlation between SMCF content and inter-particular distance.

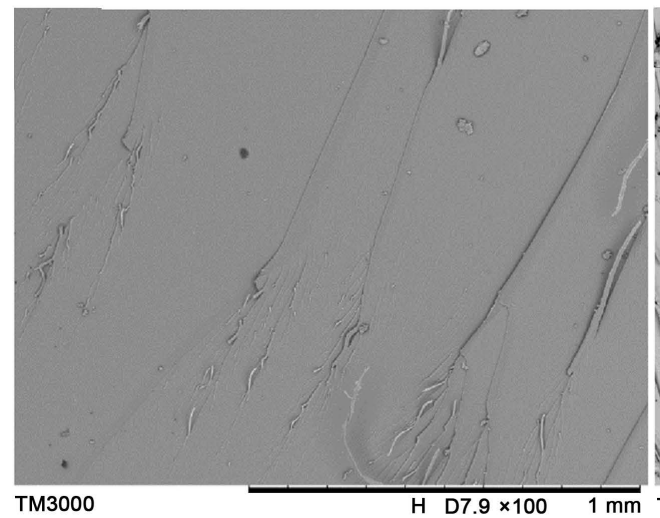

(a)

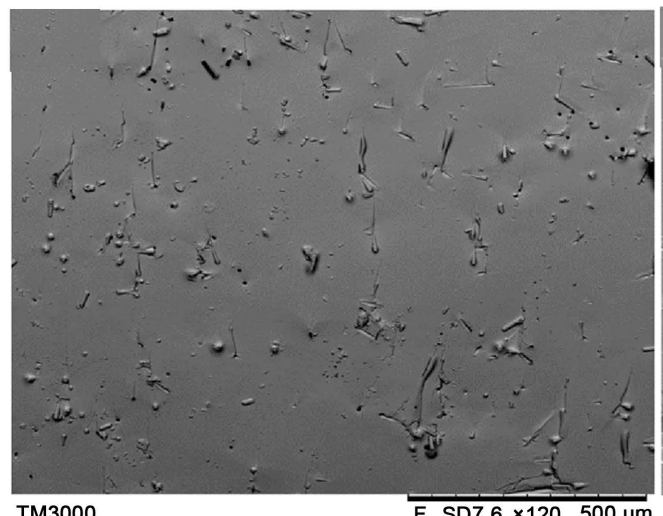

(c)

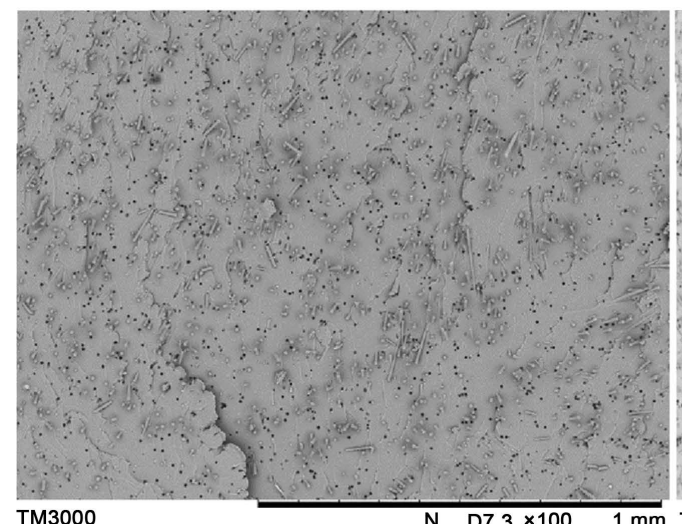

(e)

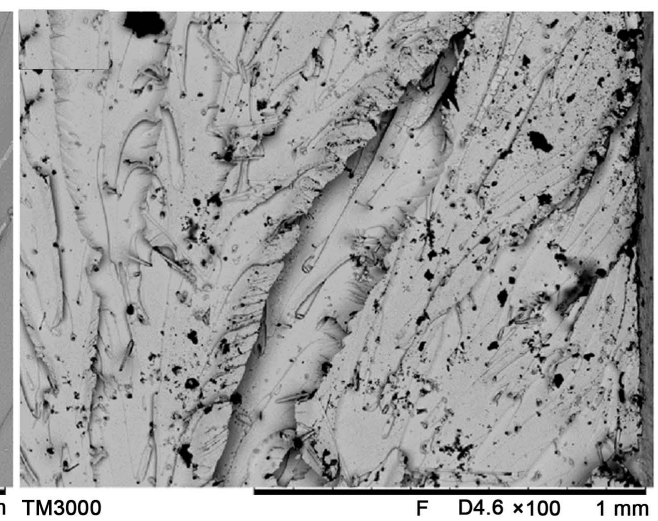

(b)

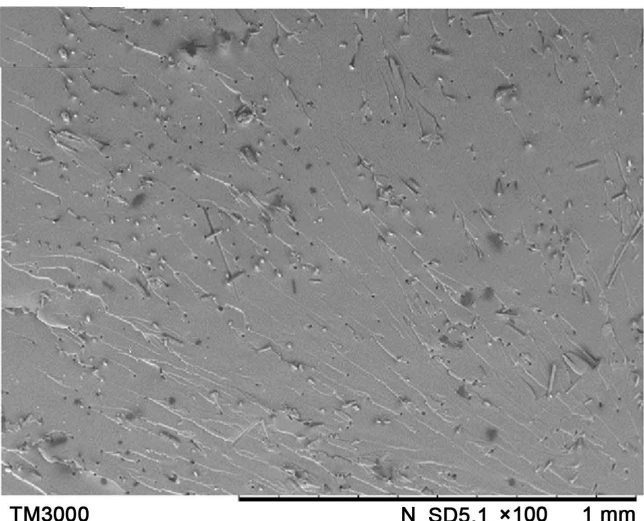

(d)

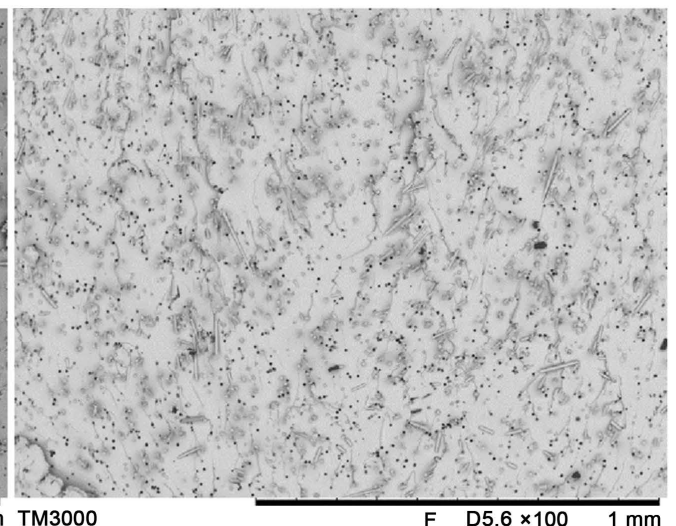

(f)

Figure 14. SEM images of ESMCF composites fracture surfaces in fast crack growth. 


\section{Conclusions}

1) This study uses FTIR spectroscopy to effectively monitor the curing kinetics of neat epoxy and SMCFreinforced epoxy. The presence of impurity elements exposed on the surface of SMCF does not show any hindrance to the curing reaction of DGEBA. FTIR also helps to decide the optimum curing time of epoxy-SMCF composite systems studied in this work. At room temperature, within 1 day, $70 \%$ curing is obtained; and by end of 8 days $99 \%$ curing results.

2) The Raman spectra of SMCF and epoxy on the fracture surfaces indicate that there is no chemical reaction between SMCF and epoxy.

3) XRD proves that after addition of the more crystalline phase SMCF to amorphous epoxy slightly reduces the crystallinity of the neat epoxy.

4) With $10 \%$ SMCF addition, there is an $11 \%$ increase in Vickers microhardness value implying the $10 \%$ SMCF modified epoxy will be more resistant to abrasion.

5) Comparison of theoretical and experimental studies of density and volume fraction showed that systems with higher SMCF contents were associated with more uniformity in distribution of SMCF fiber in the epoxy matrix.

\section{Acknowledgements}

This research is sponsored by the Australian Research Council through the ARC Discovery Scheme under the project DP120101708 involving UNSW Australia, Monash University Australia and North Carolina State University USA. Authors wish to thank Dr Pramod Koshy of UNSW SMSE for his helpful advice in the XRD aspects of this research.

\section{References}

[1] Shivamurthy, B., Udaya Bhat, K. and Anandhan, S. (2013) Mechanical and Sliding Wear Properties of Multi-Layered Laminates from Glass Fabric/Graphite/Epoxy Composites. Materials \& Design, 44, 136-143. http://dx.doi.org/10.1016/j.matdes.2012.07.059

[2] Myers, J.J. (2007) External Strengthening of Structures Using Fibre-Reinforced Polymer Composites In: Karbhari, V., Ed., Durability of Composites for Civil Structural Applications, Woodhead Publishing Limited, Cambs, 247-283. http://dx.doi.org/10.1533/9781845693565.2.247

[3] Hollaway, L.C. (2010) A Review of the Present and Future Utilisation of FRP Composites in the Civil Infrastructure with Reference to Their Important In-Service Properties. Construction and Building Materials, 24, 2419-2445. http://dx.doi.org/10.1016/j.conbuildmat.2010.04.062

[4] Dawood, M. and Rizkalla, S. (2010) Environmental Durability of a CFRP System for Strengthening Steel Structures. Construction and Building Materials, 24, 1682-1689. http://dx.doi.org/10.1016/j.conbuildmat.2010.02.023

[5] Bandyopadhyay, S. (1990) Review of the Microscopic and Macroscopic Aspects of Fracture of Unmodified and Modified Epoxy Resins. Materials Science and Engineering: A, 125, 157-184.

http://dx.doi.org/10.1016/0921-5093(90)90167-2

[6] Low, I.M., Mai, Y.W., Bandyopadhyay, S. and Silva, V.M. (1987) New Toughened-Hybrid Epoxies. Materials Forum, 10, 6 .

[7] Wetzel, B., Rosso, P., Haupert, F. and Friedrich, K. (2006) Epoxy Nanocomposites_Fracture and Toughening Mechanisms. Engineering Fracture Mechanics, 73, 2375-2398. http://dx.doi.org/10.1016/j.engfracmech.2006.05.018

[8] Buggy, M., Farragher, L. and Madden, W. (1995) Recycling of Composite Materials. Journal of Materials Processing Technology, 55, 448-456. http://dx.doi.org/10.1016/0924-0136(95)02037-3

[9] De Marco, I., Legarreta, J.A., Laresgoiti, M.F., Torres, A., Cambra, J.F., Chomón, M.J., Caballero, B. and Gondra, K. (1997) Recycling of the Products Obtained in the Pyrolysis of Fibre-Glass Polyester SMC. Journal of Chemical Technology \& Biotechnology, 69, 187-192. http://dx.doi.org/10.1002/(SICI)1097-4660(199706)69:2<187::AID-JCTB710>3.0.CO;2-T

[10] Pickering, S.J. (2006) Recycling Technologies for Thermoset Composite Materials-Current Status. Composites Part A: Applied Science and Manufacturing, 37, 1206-1215. http://dx.doi.org/10.1016/j.compositesa.2005.05.030

[11] Yang, S.M. (2009) Investigation into Recycling Carbon Fibre (Honours Project). University of Plymouth, Plymouth.

[12] Ushikoshi, K., Nobuyuki, K. and Morihiko, S. (1995) Recycling of CFRP by Pyrolysis Method. Journal of the Society of Materials Science, Japan, 44, 428-431. http://dx.doi.org/10.2472/jsms.44.428 
[13] Chand, N. and Naik, A.M. (2008) Development and High Stress Abrasive Wear Behavior of Milled Carbon FiberReinforced Epoxy Gradient Composites. Polymer Composites, 29, 736-744. http://dx.doi.org/10.1002/pc.20450

[14] Vasconcelos, P.V., Lino, F.J., Magalhaes, A. and Neto, R.J.L. (2005) Impact Fracture Study of Epoxy-Based Composites with Aluminium Particles and Milled Fibres. Journal of Materials Processing Technology, 170, 277-283. http://dx.doi.org/10.1016/j.jmatprotec.2005.05.006

[15] Chand, N. and Nigrawal, A. (2008) Investigations on d.c. Conductivity Behaviour of Milled Carbon Fibre Reinforced Epoxy Graded Composites. Bulletin of Materials Science, 31, 665-668. http://dx.doi.org/10.1007/s12034-008-0105-2

[16] Cholake, S., Mada, M., Raman, R., Bai, Y., Zhao, X., Rizkalla, S. and Bandyopadhyay, S. (2014) Quantitative Analysis of Curing Mechanisms of Epoxy Resin by Mid- and Near-Fourier Transform Infra Red Spectroscopy. Defence Science Journal, 64, 314-321. http://dx.doi.org/10.14429/dsj.64.7326

[17] Mcnally, T., Boyd, P., Mcclory, C., Bien, D., Moore, I., Millar, B., Davidson, J. and Carroll, T. (2008) Recycled Carbon Fiber Filled Polyethylene Composites. Journal of Applied Polymer Science, 107, 2015-2021. http://dx.doi.org/10.1002/app.27253

[18] Scheinbeim, J.I., Newman, B.A. and Sen, A. (1986) Field-Induced Crystallization in Highly Plasticized Poly(Vinylidene Fluoride) Films. Macromolecules, 19, 1454-1458. http://dx.doi.org/10.1021/ma00159a029

[19] Benedetti, A., Cocco, G., Fagherazzi, G., Locardi, B. and Meriani, S. (1983) X-Ray Diffraction Methods to Determine Crystallinity and Preferred Orientation of Lithium Disilicate in Li-Zn-Silicate Glass-Ceramic Fibres. Journal of Materials Science, 18, 1039-1048. http://dx.doi.org/10.1007/BF00551972

[20] Liu, Y., Xue, J.S., Zheng, T. and Dahn, J.R. (1996) Mechanism of Lithium Insertion in Hard Carbons Prepared by Pyrolysis of Epoxy Resins. Carbon, 34, 193-200. http://dx.doi.org/10.1016/0008-6223(96)00177-7

[21] Krumova, M., Klingshirn, C., Haupert, F. and Friedrich, K. (2001) Microhardness Studies on Functionally Graded Polymer Composites. Composites Science and Technology, 61, 557-563. http://dx.doi.org/10.1016/S0266-3538(00)00228-1

[22] Xie, Y. and Sherwood, P.M.A. (1990) X-Ray Photoelectron-Spectroscopic Studies of Carbon Fiber Surfaces. 11. Differences in the Surface Chemistry and Bulk Structure of Different Carbon Fibers Based on Poly(Acrylonitrile) and Pitch and Comparison with Various Graphite Samples. Chemistry of Materials, 2, 293-299. http://dx.doi.org/10.1021/cm00009a020

[23] Jiang, G., Pickering, S.J., Lester, E.H., Turner, T.A., Wong, K.H. and Warrior, N.A. (2009) Characterisation of Carbon Fibres Recycled from Carbon Fibre/Epoxy Resin Composites Using Supercritical n-Propanol. Composites Science and Technology, 69, 192-198. http://dx.doi.org/10.1016/j.compscitech.2008.10.007

[24] Jiang, G., Pickering, S.J., Walker, G.S., Wong, K.H. and Rudd, C.D. (2008) Surface Characterisation of Carbon Fibre Recycled Using Fluidised Bed. Applied Surface Science, 254, 2588-2593. http://dx.doi.org/10.1016/j.apsusc.2007.09.105

[25] Zhao, F. and Huang, Y. (2011) Grafting of Polyhedral Oligomeric Silsesquioxanes on a Carbon Fiber Surface: Novel Coupling Agents for Fiber/Polymer Matrix Composites. Journal of Materials Chemistry, 21, 3695. http://dx.doi.org/10.1039/c0jm03128c

[26] Yip, H.L.H., Pickering, S.J. and Rudd, C.D. (2002) Characterisation of Carbon Fibres Recycled from Scrap Composites Using Fluidised Bed Process. Plastics, Rubber and Composites, 31, 278-282. http://dx.doi.org/10.1179/146580102225003047

[27] Semoto, T., Tsuji, Y., Tanaka, H. and Yoshizawa, K. (2013) Role of Edge Oxygen Atoms on the Adhesive Interaction between Carbon Fiber and Epoxy Resin. The Journal of Physical Chemistry C, 117, 24830-24835. http://dx.doi.org/10.1021/jp407835d

[28] Kreling, S., Fischer, F., Delmdahl, R., Gabler, F. and Dilger, K. (2013) Analytical Characterization of CFRP Laser Treated by Excimer Laser Radiation. Lasers in Manufacturing, 41, 282-290. http://dx.doi.org/10.1016/j.phpro.2013.03.080

[29] Peijs, A.J.M., Catsman, P., Govaert, L.E. and Lemstra, P.J. (1990) Hybrid Composites Based on Polyethylene and Carbon Fibres Part 2: Influence of Composition and Adhesion Level of Polyethylene Fibres on Mechanical Properties. Composites, 21, 513-521. http://dx.doi.org/10.1016/0010-4361(90)90424-U

[30] Ko, Y.S., Forsman, W.C. and Dziemianowicz, T.S. (1982) Carbon Fiber-Reinforced Composites: Effect of Fiber Surface on Polymer Properties. Polymer Engineering and Science, 22, 805-814. http://dx.doi.org/10.1002/pen.760221304

[31] Hüttinger, K.J., Krekel, G. and Zielke, U. (1994) Evidence for Chemical Bond Formation between Surface Treated Carbon Fibres and High Temperature Thermoplastics. Journal of Applied Polymer Science, 51, 737-742. http://dx.doi.org/10.1002/app.1994.070510420

[32] Gonzlez, M., Carlos, J. and Baselga, J. (2012) Applications of FTIR on Epoxy Resins-Identification, Monitoring the Curing Process, Phase Separation and Water Uptake. In: Theophile, D.T., Ed., Infrared Spectroscopy—Materials Sci- 
ence, Engineering and Technology, InTech, Rijeka, 261-284. http://dx.doi.org/10.5772/36323

[33] Smith, R.E., Larsen, F.N. and Long, C.L. (1984) Epoxy Resin Cure. II. FTIR Analysis. Journal of Applied Polymer Science, 29, 3713-3726. http://dx.doi.org/10.1002/app.1984.070291207

[34] Finzel, M.C., Delong, J. and Hawley, M.C. (1995) Effect of Stoichiometry and Diffusion on an Epoxy-Amine Reaction Mechanism. Journal of Polymer Science Part A: Polymer Chemistry, 33, 673-689. http://dx.doi.org/10.1002/pola.1995.080330409

[35] Chike, K.E., Myrick, M.L., Lyon, R.E. and Angel, S.M. (1993) Raman and Near-Infrared Studies of an Epoxy Resin. Applied Spectroscopy, 47, 1631-1635. http://dx.doi.org/10.1366/0003702934334714

[36] Nikolic, G., Zlatkovic, S., Cakic, M., Cakic, S., Lacnjevac, C. and Rajic, Z. (2010) Fast Fourier Transform IR Characterization of Epoxy GY Systems Crosslinked with Aliphatic and Cycloaliphatic EH Polyamine Adducts. Sensors (Basel), 10, 684-696. http://dx.doi.org/10.3390/s100100684

[37] Poisson, N., Lachenal, G. and Sautereau, H. (1996) Near- and Mid-Infrared Spectroscopy Studies of an Epoxy Reactive System. Vibrational Spectroscopy, 12, 237-247. http://dx.doi.org/10.1016/0924-2031(96)00027-6

[38] Strehmel, V. and Scherzer, T. (1994) Structural Investigation of Epoxy Amine Network by Mid and near Infra-Red Spectroscope. European Polymer Journal, 30, 361-368. http://dx.doi.org/10.1016/0014-3057(94)90300-X

[39] Lapique, F. and Redford, K. (2002) Curing Effects on Viscosity and Mechanical Properties of a Commercial Epoxy Resin Adhesive. International Journal of Adhesion and Adhesives, 22, 337-346. http://dx.doi.org/10.1016/S0143-7496(02)00013-1

[40] Bandyopadhyay, S. (1982) A Study of the Volumetric Setting Shrinkage of Some Dental Materials. Journal of Biomedical Materials Research, 16, 135-144. http://dx.doi.org/10.1002/jbm.820160206

[41] Tuinstra, F. (1970) Raman Spectrum of Graphite. The Journal of Chemical Physics, 53, 1126. http://dx.doi.org/10.1063/1.1674108

[42] Montes-Morán, M.A. and Young, R.J. (2002) Raman Spectroscopy Study of High-Modulus Carbon Fibres: Effect of Plasma-Treatment on the Interfacial Properties of Single-Fibre-Epoxy Composites. Carbon, 40, 857-875. http://dx.doi.org/10.1016/S0008-6223(01)00207-X

[43] Darmstadt, H., Sümmchen, L., Ting, J.M., Roland, U., Kaliaguine, S. and Roy, C. (1997) Effects of Surface Treatment on the Bulk Chemistry and Structure of Vapor Grown Carbon Fibers. Carbon, 35, 1581-1585. http://dx.doi.org/10.1016/S0008-6223(97)00116-4

[44] Kudin, K.N., Ozbas, B., Schniepp, H.C., Prud'homme, R.K., Aksay, I.A. and Car, R. (2008) Raman Spectra of Graphite Oxide and Functionalized Graphene Sheets. Nano Letters, 8, 36-41. http://dx.doi.org/10.1021/nl071822y

[45] Bal, S. (2010) Experimental Study of Mechanical and Electrical Properties of Carbon Nanofiber/Epoxy Composites. Materials \& Design, 31, 2406-2413. http://dx.doi.org/10.1016/j.matdes.2009.11.058

[46] Rajan, A.S., Sampath, S. and Shukla, A.K. (2014) An in Situ Carbon-Grafted Alkaline Iron Electrode for Iron-Based Accumulators. Energy \& Environmental Science, 7, 1110. http://dx.doi.org/10.1039/c3ee42783h

[47] Mahanandia, P., Schneider, J.J., Engel, M., Stuhn, B., Subramanyam, S.V. and Nanda, K.K. (2011) Studies towards Synthesis, Evolution and Alignment Characteristics of Dense, Millimeter Long Multiwalled Carbon Nanotube Arrays. Beilstein Journal of Nanotechnology, 2, 293-301. http://dx.doi.org/10.3762/bjnano.2.34

[48] Kumar, V., Sonkawade, R.G., Chakarvarti, S.K., Singh, P. and Dhaliwal, A.S. (2012) Carbon Ion Beam Induced Modifications of Optical, Structural and Chemical Properties in PADC and PET Polymers. Radiation Physics and Chemistry, 81, 652-658. http://dx.doi.org/10.1016/j.radphyschem.2012.02.027

[49] Mallick, B., Behera, R.C., Tiwari, T.N., Panigrahi, S. and Samal, S.K. (2008) X-Ray Diffraction and Raman Scattering Studies of Proton-Induced, Modified Polyethylene Terephthalate Microfiber. Radiation Effects and Defects in Solids, 163, 149-159. http://dx.doi.org/10.1080/10420150701640066

[50] Khalaf, H.A., Mansour, S.E. and El-Madani, E.A. (2011) The Influence of Sulfate Contents on the Surface Properties of Sulfate-Modified Tin(IV) Oxide Catalysts. Journal of the Association of Arab Universities for Basic and Applied Sciences, 10, 15-20. http://dx.doi.org/10.1016/j.jaubas.2011.06.003

[51] Manna, U., Richardson, R.M., Fukuda, A. and Vij, J.K. (2010) X-Ray Diffraction Study of Ferroelectric and Antiferroelectric Liquid Crystal Mixtures Exhibiting de Vries SmA*-SmC Transitions. Physical Review E, 81, Article ID: 050701.

[52] Veeresh Kumar, G.B., Rao, C.S.P., Selvaraj, N. and Bhagyashekar, M.S. (2010) Studies on Al6061-SiC and Al7075$\mathrm{Al}_{2} \mathrm{O}_{3}$ Metal Matrix Composites. Journal of Minerals \& Materials Characterization \& Engineering, 9, 43-55.

[53] Baltá-Calleja, F.J.F.S. (2007) Microhardness of Polymers. Cambridge University Press, Cambridge.

[54] Krumova, M., Fakirov, S., Calleja, F.J.B. and Evstatiev, M. (1998) Structure Development in PET/PA6 Microfibrillar- 
Reinforced Composites as Revealed by Revealed by Microhardness. Journal of Materials Science, 33, 2857-2868. http://dx.doi.org/10.1023/A:1017594021634

[55] Balta Calleja, F.J., Santa Cruz, C., Sawatari, C. and Asano, T. (1990) New Aspects of the Microstructure of Polyethylene-Isotactic Polypropylene Gel Blends as Revealed by Microhardness: Influence of Composition. Macromolecules, 23, 5352-5355. http://dx.doi.org/10.1021/ma00228a008 